\title{
Improving Economic Empowerment Programs for Low-Income Women in Saudi Society: A Study Applied to Charities' Beneficiaries in Riyadh
}

\author{
Jehan Lardhi \\ Assist. Professor of Social Work, \\ College of Social Work, \\ Princess Nourah bint Abdulrahman University, \\ Saudi Arabia
}

DOI: https://doi.org/10.36941/jesr-2020-0076

Abstract

The current study aims to improve low-income women's economic empowerment programs in Saudi society from the perspectives of low-income women benefiting from these programs. It also seeks to identify the degree of low-income women's economic empowerment in Saudi charities, outline the obstacles that hinder low-income women's economic empowerment, and introduce proposals to improve the level of low-income women's economic empowerment. To achieve these objectives, the analytical descriptive approach was adopted, quantitative and qualitative techniques were utilized to collect, analyze, and interpret data. A questionnaire was prepared by the author and applied to a sample of (198) low-income women benefiting from Bunyan, a Saudi charitable society. The results demonstrated that there was a medium level of charities' contribution to low-income women's economic empowerment in Saudi society. The degree of the obstacles hindering low-income women's economic empowerment in charitable societies was very high. The participants agreed that the solutions proposed to improve the level of low-income women's economic empowerment were very good. The study recommends holding workshops and conferences to discuss the standards and indicators of low-income women's economic empowerment in charitable societies. It also recommends delivering lectures and rehabilitation training to educate women and raise their awareness about the economic sectors and the importance of exchanging experiences at the local and global levels.

Keywords: Economic empowerment, low-income women, charity, Saudi society

\section{Introduction}

Woman is the mirror of social development. Her status is a criterion for evaluating the degree of social progress and commitment to the values and principles of the third millennium. The last decades have witnessed unstopped talk about the crucial role played by women, stressing the necessity of their empowerment in the varied fields of life. International conferences and summits have called for engaging woman in the processes of development because no success could be achieved without her participation. She represents a sustainable human resource and a crucial power that has control over not only half, but all of the social resources. According to a study conducted by the World Bank (2014), empowering women can contribute to reducing hunger all over the world by 12-17\%. It also leads to family stability, economic growth, and investment opportunities increase. Further, women's economic empowerment raises GDP up to $34 \%$ in many countries. Therefore, about 865 million women around the world contribute to their national economies (Abdelrazq, Hamad, Ali, Mohammed, \& Kamal, 2016; Aguirre, Hoteit, Rupp, \& Sabbagh, 2012; Maaytah, 2010). 
However, we find that women's economic contributions are limited, especially when compared to men's contributions. This situation is an implication for the traditional role ascribed to women that confined her to social contributions by supporting and preserving family structures and values (Saqib, Aggarwal \& Rashid, 2016). King Khalid Foundation reported that Saudi women's economic freedom and life quality have been negatively affected by the limited job opportunities available for them, as $63.4 \%$ of the unemployed are women and most of them live in low-income families (Hartnell, 2018).

Women's organizations, societies, and leaderships all over the world have succeeded to gain local, regional, and international support for the fifth goal of the Sustainable Development Goals (SDGs) 2015-2030. It perceives women's empowerment and gender equality as crucial to economic growth and sustainable development. Therefore, setting-up policies for empowering women represents a top priority for many countries. The Secretary-General of the United Nations held a high-level convening to discuss the possible ways and techniques that help achieve the fifth goal of the SDGs (Nassar, Khafagy, \& El-Khouly, 2017).

The currently rapid changes and strong transformations have generated a new thought towards women's empowerment and their role in facing economic and developmental challenges. Thus, global and Arabic key stakeholders demand on women's participation in the comprehensive development process that will lead to further economic development and prosperity, increased competitiveness and enhanced equality (Women management and leadership, 2017).

Empowerment is a strategy or policy pursued during a certain period of time, which goes through a set of stages and its main driver is the human being. It thus includes any step that develops women's participation, abilities, awareness and knowledge. It results in increasing women's selfesteem physically, psychologically, socially, economically and politically. It means also the recognition and employment of women's potentials and capabilities by enabling them to have control and to contribute freely and consciously to society building (At-Tarif, 2014; Kazuz, 2016).

By female empowerment, we refer to her right to make choices and decisions, particularly those relevant to her own life and future. It means also to enable women to leave their fingerprints and to influence their surroundings and communities (Abdul Salam, 2005). It seeks to raise women's awareness about critical issues such as gender equality, domestic violence, and discrimination, in addition to boosting self-confidence and self-faith among them by highlighting their potentials, abilities, and capabilities to perform various roles and to enter all fields (Mohamed, 2007). Empowerment enhances participation and boosts the equality of individuals' rights and duties. As emphasized by Mohamed (2004), the social activities and programs introduced by women's developmental societies play an integral role in the process of women's empowerment.

Women's economic empowerment is one of the main strategies of social development and advancement. Recent UN conferences highly recommended the inclusion of women in the process of development and participation in the decision-making, leadership and planning. Global organizations and foundations adopt equality-oriented policy that assures providing unbiased opportunities of empowerment and participation (Kashroud, 2019).

According Nassar, Khafagy, and El-Khouly (2017), there is a strong relation between women's economic empowerment and the welfare of the family and the society, since it leads to an increase in the family living condition. Furthermore, raising the proportion of female economic participation to equal male participation increases the GDP of the USA by $5 \%$, of Japan by $9 \%$, of the UAE by $12 \%$, and of Egypt by 34\% (Aguirre et al., 2012).

Leaders and officials in KSA have adopted strategies and politics oriented towards the women's economic empowerment and activating their role in the great advancement witnessed by the Saudi society. They are crucial to sustainable development as enhanced by the fifth objective of the Saudi Vision 2030 that enhances gender equality and women's empowerment. Remarkable efforts are made by KSA leaders to promote woman rights, provide equal opportunities in education and training, and to increase women's inclusion in the labor market. As highlighted in Vision 2030, KSA supports and encourages female leadership in the political and economic fields.

In a word, women's economic empowerment is a scale for social progress and advancement that 
promote sustainable development and boost human potentials.

Despite the importance of woman empowerment, in general, and her economic empowerment in particular, and the positive relationship between women's economic empowerment and economic growth, the fruits and benefits of development are not always distributed fairly between men and women. As such, economic growth may not lead inevitably to women's economic empowerment. Therefore, achieving women's economic empowerment requires setting-up plans and making efforts that address the various factors that pull it back.

In addition, women's economic empowerment is a relatively modern concept emerged in the nineties of the last century in international forums and mass media. Therefore, there is no clear or common understanding of what it means, instead different definitions and consequently varied implications, policies, and programs (Akour, 2015).

KSA has paid special attention to low-income women by regarding them not as a social burden, but as an economic power. The measures taken to support those women include drawing a future vision to afford good job opportunities for them and implementing women's economic empowerment programs and projects. Shahri (2013) and Saif (2010) agreed that these programs and projects helped create job opportunities and startups for income-low women, in addition to reducing their underemployment ratios in KSA. Women participated in these programs were driven by their willingness to achieve financial independence and empowerment. As emphasized by Hunt and Samman (2016), enabling poor and low-income women requires concerted, targeted efforts that prioritize women's needs and preferences, recognize their heterogeneity, and develop strategies to ensure equitable outcomes.

The projects of productive families represent a paradigm for women's small business. They afford work opportunities for them and enable home-based production and management of projects. Women of these families can gain money and achieve financial independence by developing their products. The concept of productive families differs from one society to another and according to the nature of the programs that sponsor them. However, there is a common agreement on the main goal of these programs, seeking to improve the social and economic conditions of poor families by providing training courses for them and developing their abilities to do simple crafts and start up their own business (El-sharif, \& Albraithen, 2018).

Therefore, the current study seeks to improve the programs of low-income women's economic empowerment in Saudi society by exploring the services offered by charitable societies to enable lowincome women to delve into the labor market. It also identifies the obstacles that hinder low-income women's economic empowerment and introduces proposals to improve the plans and policies of the programs and projects intended to empower low-income women in KSA.

\section{Statement of the Problem}

The programs provided by charitable societies face many problems and obstacles that hinder the economic empowerment of Saudi women with low-income and their participation in the labor market. It necessitates doubling our efforts to enable them economically, so they can participate in achieving comprehensive, sustainable development. Another problem is that, though there are plenty of charitable societies in KSA calling for women's economic empowerment, there is a gap between the services provided and female participation in the economy. Notwithstanding, there is a remarkable decline in males and females unequal participation in the labor market. However, unemployment rates among Saudi women still high and their economic contributions are weak compared to global and regional standards. The World Economic Forum (2017) reported that KSA ranks the $12^{\text {th }}$ regionally and the 133 globally in terms of women's participation in workforce. Further, the workforce survey done by the Saudi Central Bureau of Statistics in 2019 showed that the unemployment rate among Saudi males is $5.2 \%$, while it reached $21 \%$ among Saudi females.

To have a closer look about these problems, the author conducted interviews with (11) lowincome women benefiting from the services and programs provided by (3) charitable societies in 
Riyadh. She surveyed their opinions by asking them: Does the charity provide training programs for low-income women's economic empowerment? What are the kinds of programs or projects provided by these societies to empower low-income women economically? Are the provided training programs and projects sufficient for low-income women economic empowerment?

The results of the interviews can be summarized in the following main points:

- 9 of the interviewed women, i.e. $81.82 \%$, agreed that there is a low level of the economic empowerment programs offered to them by these charities;

- 7 of the interviewed women, i.e. $63.64 \%$, demonstrated that charities provide various projects and training programs including, design, photography, make-up, sewing, cooking, printing, manufacture of perfumes, party planning, and hosting, as cooking and cosmetics are the most common;

- 6 of the interviewed women, i.e. $54.55 \%$, assured that the training programs and projects are practical and intensive, but they lack marketing procedures and strategies, and they demanded on more support and flexibility in the implementation of the projects.

Therefore and in the light of KSA orientation towards increasing women's economic participation, the current study attempts to answer the following main question: How can the programs of low-income women's economic empowerment in Saudi society be improved?

From this question, the following sub-questions are derived:

1. What is the level of low-income women's economic empowerment in Saudi charities?

2. What are the obstacles that hinder low-income women's economic empowerment in Saudi charities?

3. What are the proposed solutions to improve the level of low-income women's economic empowerment in Saudi charities?

\section{Objectives}

The current study aims to identify the level of low-income women's economic empowerment in Saudi charities. It also seeks to underline the obstacles that hinder low-income women's economic empowerment in Saudi charities and to propose solutions to improve the level of low-income women's economic empowerment in Saudi charities.

\section{Significance}

The reality of low-income women's economic empowerment in charitable societies, its challenges and solutions is of great vitality to Saudi society. To the author's knowledge, no previous study has dealt with the programs and activities provided by charities in KSA. Identifying the role played by charitable societies is essential to help improve the services provided for low-income women. The study results and suggestions can be utilized to reduce women underemployment and to develop practical solutions to enable low-income Saudi women's participation in the labor market. Saudi leaders and decision-makers can benefit from the study results by developing plans for increasing low-income women's economic empowerment and promoting the programs prepared to achieve this purpose. The current study raises Saudi social awareness about the importance of the economic empowerment of women and the role played by charitable societies in boosting low-income women's economic empowerment. The current study is of special importance for charitable societies, since it provides a feedback about the obstacles and challenges that face the implementation of the programs of low-income women's empowerment. It also provides a guide of probable solutions and suggestions for the improvement of these programs. Another significance of the study is its accordance with Saudi Vision 2030 as it sheds a light on the tools of economic empowerment and the dimensions of sustainable development. Finally, it opens the gate before scholars and authors to conduct more future studies about women empowerment in various fields of life. 


\section{Limitation}

Spatial and human limitations: A group of low-income women who benefit from the services provided by Bunyan.

Temporal limitations: data collection took four months from January to April 2019.

Objective limitations: improving the programs of low-income women's economic empowerment in Saudi community by identifying the level of their economic empowerment, the obstacles that hinder their economic empowerment, and the proposals to improve it.

\section{Conceptual Framework \& Literature Review}

\subsection{The concept of women's economic empowerment:}

The OECD (2011) defines women's economic empowerment as the capacity of women to participate in, contribute to and benefit from growth processes in ways which recognize the value of their contributions, respect their dignity and make it possible to negotiate a fairer distribution of the benefits of growth.

According to a report prepared by the Secretariat of the United Nations Inter-Agency Task Force, women's empowerment has five components: women's sense of self-worth; their right to have and to determine choices; their right to have access to opportunities and resources; their right to have the power to control their own lives, both within and outside the home; and their ability to influence the direction of social change to create a more just social and economic order, nationally and internationally (UNFPA, 2005).

The author defines women's economic empowerment as creating the appropriate environment in charitable societies in which Saudi women become aware, influential, confident, and able to address inequality and to take the proper decisions that serve themselves and their society.

\subsection{The goals of women's economic empowerment}

Khoury, Mukhual, \& Hadeer (2006) agree that women's economic empowerment is based fundamentally on women's right to be empowered; it stands against discrimination and gender imbalances and aims at achieving gender equality by the inclusion of gender-oriented perspective in the developmental policies, programs and projects. This means allowing women's real participation in the decision-making process, starting from the family and governmental and non-governmental organizations, reaching to the highest state positions. The private sector and women's organizations should play a role in changing the prevailing negative attitudes and participate effectively in empowering women economically, since it helps eliminate all forms of violence against women, fight women's underemployment and poverty, and reform the laws and regulations that are unfair to women. Furthermore, women's economic empowerment boosts self-worthiness and self-esteem among women and helps them to redefine and rearrange their relationship with themselves, their families, and their societies (Nassar, Khafagy, \& El-Khouly, 2017).

\subsection{Factors affecting women's economic empowerment:}

Women's economic empowerment is not a quick-fix operation, but it is a multifaceted process and a long-term transformation. It perquisites the provision of administrative, professional, and developmental services for enabling women in all the fields of Life. According to Akour (2015), there are a set of underlying factors for enabling women's economic empowerment, including:

- Increasing economic opportunities for women: it means increasing female participation in all economic fields and setting-up policies that enable women's access to the labor markets and the economic choices and decisions making. 
- Increasing women's participation in economic decision-making and policies setting-up: increasing the number of effective female participation in these processes helps taking decisions in their favor, positively influences their abilities to build human capital and benefit from available economic opportunities.

- Providing decent work conditions by expansion social protection and providing social care services ... etc.

Accordingly, it can be concluded that achieving women's economic empowerment demands on interactive and multifaceted participation of Saudi women, society, and leaderships.

\subsection{The importance of women's economic empowerment:}

As mentioned previously, women's economic empowerment is based on their due right to be empowered in all fields of life. International agreements and conventions conclude that female participation in the developmental process can be achieved by modifying laws and policies and setting-up mechanisms that boost equality, demolish discrimination, correct misconceptions, and support women's abilities (UN, 2017). The achievement of women's economic empowerment results in gender equality, income increase, economic growth, and raising the level of national competitiveness. Further, it contributes to the reduction of poverty rates and the fair distribution of income since it represents a main factor of the welfare of women and families, thus achieving sustainable human development. By women's economic empowerment, various economic activities benefit from the employment of female potentials and capabilities (Adraghmah, 2014).

Given the importance of women's economic empowerment, many previous studies have covered it in various contexts. Kashroud and Marzouki (2019) aimed to study the reality of women's economic empowerment and contribution to sustainable development based on women's right to access political and economic sectors. Algeria is among the first Arabic countries that entered the field of women's empowerment by giving them access to parliamentary councils and making a cotta for female participation. Improvement in women's political participation has brought calls for women's economic empowerment and for activating their productive and active contribution in the developmental process. However, there are increasing concerns about the passive influences of social, economic, and cultural environment in Algeria. Further, fewer women's participations are counted in official statistics which recognize specific types of economic activities. Likewise, a study conducted by Al-Ghamdy (2019) to investigate the role of NGOs in achieving social development in Riyadh in the light of Saudi Vision 2030. The author administered a questionnaire on 1842 beneficiaries and 288 leaders. Findings revealed that $62.8 \%$ of participants work in more than one organizations improve their standard of living, while $86.6 \%$ work in social organizations. NGOs play an important role in maintaining sustainable social development in Saudi Arabia. Challenges to achieve 2030 vision include lack of appropriate media specialists working in NGOs. Women constituted the major beneficiaries of the NGOs services by (89\%). Topal (2019) found that women's empowerment in KSA used "pro-women reforms" as a code word to enhance competition in Saudi market by increasing foreign economic integration. Therefore, Saudi Arabia is used as a case to examine the level of women's empowerment and its role in women emancipation.

Also in KSA, Yassin (2018) conducted a study to identify the impact of women's empowerment decisions on the financial and business market according to Saudi Vision 2030, and expected the future role of Saudi women in the financial and business market. The study results demonstrated that women's empowerment can be achieved by sponsoring women's talents, investing their abilities, affording appropriate opportunities, providing safe environment and services, and securing their full rights in all fields. The study recommends conducting a study of the short- and long-term implications of the labor market policies for women's economic participation rate. In (Hartnell, 2018), the present state of philanthropy in the Arab region was explored, suggestions and implications of these organizations' roles as a contributor in social change were offered. Philanthropies in KSA 
encounter many challenges, including limited number of skillful employees by (72.9\%), grievances towards the regulations by (71.2\%), bureaucracy by (64.4\%), and inflexibility of cash flows by (64.6\%). Saudi women's business empowerment and how could they achieve success, sustainability and continuity in workplace were discussed by Kandy (2017). She adopted the descriptive approach and surveyed a number of companies employing women. Results confirmed that many fast-growing countries have decreased labor supply, which enhances taking advantage of women's potentials and talents. In the Saudi context, the study also confirmed that women are still excluded from participation in the business community and they still need a maximum degree of attention, support and empowerment. It concluded that sustainability is an essential principle that drives companies to increase women's empowerment opportunities by preparing training programs for developing women's skills and performance.

Abdel'al (2016) aimed to identify the effectiveness of microfinance institutions in women's economic empowerment in Tulkarm Governorate from the perspectives of institutions' managers and beneficiaries. The analytical descriptive, multi-method approach, interviews, and a questionnaire applied to a sample of 118 female borrower. Results showed that microfinance institutions did not contribute to women's economic empowerment as the concept of empowerment intended to mean. The study recommended applying the concept of economic empowerment, its dimensions, requirements and practices in accordance with the objectives of microfinance institutions.

Salami (2016) explored women's economic empowerment in Algeria by studying the conventions and agreements held to organize women's work and demolish discrimination. CEDAW is one of the most important assigned conventions for its obvious effects on the position of Algerian woman, including the modification of the constitution and some relevant laws. Accordingly, the rates of women's economic participation as well as their educational level have increased. As such, they gained access to more work opportunities in various domains and sectors.

Kazuz (2016) aimed to highlight the obstacles that hinder women's economic empowerment, and find solutions to them. Qualitative research, case study design, interview and questionnaire were adopted. It concluded that the unemployment rate among female workers reached $42.62 \%$. It also found that the largest obstacles to women's empowerment were the traditional view of women's work and lack of experience among women. To overcome these obstacles, more efforts should be done to change the traditional view of women's work, in addition to providing training programs to qualify women to delve into the labor market. In his study, Al-Aiban (2016) stressed the need to establish a social development organization that works to achieve sustainable development by investing the funds provided by the community organizations in a planned and permanent way, and supporting the unemployed members of poor families to set up development projects and satisfy their needs. These families are physically and morally productive, which is the basic requirement of the organization.

Peebles, Darwazeh, Ghosheh, and Sabbagh (2015) discussed the status of Jordanian women working in the private sector, and the extent of their empowerment in the workplace. The analytical descriptive approach applied to a sample of 56 working woman. The study concluded that women have suffered from varied social and legal obstacles in the private work environment. It recommended taking the necessary procedures to facilitate women's empowerment in the workplace. Moreover, Nasseef (2015) utilized a mixed-method approach and applied interviews and questionnaire survey, as the findings revealed that NGOs in Jeddah used five strategies to empower women: Guests and events, building alliances, media, religion, and framing women's issues. Religion was found to be the main factor controlling NGOs and women empowerment. The author identified the challenges facing Saudi NGOs in each of these aspects. Cultural obstacles and corruption were the two major barriers encountering women's empowerment.

At-Tarif (2014) identified the self-imposed, social, institutional and organizational obstacles of empowering women in the labor market. The analytical descriptive approach and the questionnaire were applied to a sample of 600 woman. The study found that self- imposed obstacles of empowering women in the labor market are represented incompetence and fear of failure when joining 
unconventional jobs, while social obstacles include lack of nurseries, and customs and traditions that constrains women from joining many professions. For the institutional obstacles, low wages of jobs, lack of information on the labor market requirements, lack of job opportunities available to women, and lack of training programs offered to qualify women and develop their skill.

Salami and Beeh (2013) aimed to identify the effectiveness and contribution of small and medium enterprises in women's economic empowerment according to a set of indicators. A questionnaire was distributed to a random sample of female entrepreneur in various economic sectors in Algeria. After addressing (123) questionnaires, the study concluded that women were able to manage small enterprises, as they have deficiencies in marketing and a lot of administrative and regulative problems. It recommended raising women's awareness about appropriate financing options, and conducting more research on the economic status of women.

Najm (2013) identified the role of developmental institutions in Palestinian women's empowerment and the degree of committing to the standards and indications women's empowerment, in addition to variance in the adopted standards. The analytical descriptive and content analysis method were applied to the strategic plans and annual reports of (10) institutions working in the field of women's empowerment. Results showed that the institutions under study employed varied standards and indications for women's empowerment, including social empowerment, educational empowerment, economic empowerment, political empowerment, and health empowerment, respectively. The study recommended promoting partnership strategies and programs between private and public institutions sought to women's empowerment.

A study by Shahri (2013) found that dedicated projects that create job opportunities in small businesses were most likely to help low-income women and reduce unemployment in KSA. The most important motivation for women to participate in such initiatives was to gain financial autonomy and thus promote women's empowerment. Aloulou (2015) on the other hand explored various mechanisms of entrepreneurship development for Saudi women. He emphasized the role of entrepreneurship programs to build entrepreneurial and creative projects, the employment of ICT and social media for marketing their businesses, and the corporate community responsibility, and funding. He based his research on a literature review and desk research on women's economic empowerment. Rahman and Sultana (2012) aimed to identify the degree of societies' participation in women's psychological, social and economic empowerment. A questionnaire was applied to a sample of (69) female of a society in Hyderabad. It concluded that the society has contributed positively to women's psychological, social and economic empowerment by affording more than 350 work opportunities for illiterate and semi-illiterate women.

Al-Kharouf and Al-Hadidi (2011) evaluated the project of developmental prosperity in relation to Jordanian women's empowerment from the perspectives of women who joined the project. The descriptive approach was adopted and a form was distributed to a sample of (170) woman. Participants expressed a high degree of satisfaction about the project since it promoted women's economic empowerment by $50 \%$ and increased their self-confidence and decision-make abilities.

Khan and Bibi (2011) evaluated the implications of operating a participatory development project for women's social and economic empowerment and poverty reduction in Nasirabad, Pakistan. The tools include a questionnaire, observation, and interview applied to (165) female beneficiaries. The investigated empowerment indicators include the ability to build group capacities, work burden alleviation, participation in economic activities, access to financial and economic institutions, and ability to take decisions on expenditure. The results showed an improvement in some indicators such as building group capacities, participation in economic activities, and access to financial and economic institutions.

The results of Al-Khamshi (2011) revealed that there is no national strategy for productive families, which led to the lack of coordination and networking efforts, the complexity of administrative procedures, and the negative perception of some professions or quality of work. This affects the psychology of women working in the project and their production. Similarly, Derbal (2011) investigated the voluntary sector in Jeddah including the welfare association; the charity 
organization; and corporate giving of companies. The author focused on women and teens. He suggested that philanthropy could be the start for a professional career in which Saudi women acquire the skills to perform some jobs through their collaboration with philanthropy in business and compete with men.

Hoque and Yoshihito (2009) identified the impact of micro-credit programmers in empowering rural women in Bangladesh. A structured questionnaire was applied to 180 women of Rampur village, $50 \%$ of them were active members of NGOs and the rest were housewives. The study revealed that only $21 \%$ of the respondent women are empowered and $69 \%$ of them are the active members of micro-credit programs. The socio-economic factors of the women institutional participation, media exposure and family land holdings are very important for women empowerment. El-Sayed and Amara (2008) studied the role of NGOs in providing poor women with knowledge, skills and guidelines required for understanding the labor market mechanisms. They also covered the obstacles that confined poor woman to benefit from the programs and services provided by NGOs. Interview form was utilized to 85 beneficiaries, members and specialists of a private society. The study concluded that private societies are still incapable of providing poor women with knowledge, skills and guidelines required for understanding the labor market mechanisms. Further, poor women face many challenges in dealing with labor market mechanisms and benefiting from the programs and services provided by the societies.

Challenges of women's economic empowerment:

Kazim (2016), Amal, Halwas, Najar, Shukry, Ketab and Amrah (2013), and Akour (2015) explored the challenges and obstacles that hinder women's economic empowerment, including:

1- Women's weak skills: It is related to the level of their education, training, qualifications, and skills that enable them to enter the labor market and the knowledge-based economy. Lack of communication and information technology skills hinders women's economic empowerment. Women's low participation in skills training programs can be interpreted by the responsibility they have towards their family and child caring duties.

2- Lack of economic resources ownership and control: Ownership of the means of production, capital and control of resources is one of the most important indicators of a woman's economic position and strength, and women have been excluded from managing economic resources, while they themselves are used as an element in managing these resources

3- Poor infrastructure and services: for example, lack of transportation, water, sanitation, ... etc. may lead to limited and scarce opportunities for economic activity and women not breaking into the economic field

4- Limited markets: Women encounters many restrictions due to many factors related to their family responsibility and cultural practices, and therefore they get no access to market information about products and inputs, and therefore they depend on intermediaries who buy their products at prices below the market price.

5- Social restrictions: Women in the Arab world are restrained by a narrow social view that reduces her role in economic development.

6- Self-imposed obstacles: Many women have a limited perception of their capabilities and roles, which prevents them from benefiting from the opportunities available to them. It detained them for formal participations in important events, acquisition of effective roles and leadership status. Despite enacting many laws and legislations that guarantee women's participation opportunities, they do not benefit from them. It emphasizes the importance of educating women and raising their awareness about their rights of empowerment.

According to Kazim (2016), weak effectiveness of women's organizations is an additional obstacle to support the orientation of women's economic empowerment. It can be attributed to many factors such as lack of financial resources for supporting these organizations, in addition to lack of strategies for receiving national support. women's organizations have no data and statistics about women participating in economy, the nature of their participation and their needs. The global economic crises have created more obstacles, such as low demand for exports and slow cash flow. 
Surprisingly, most women's organizations have no comprehensive strategy for women's economic empowerment, and more above they have a weak awareness of the importance of empowerment and its true conception, standards, and indicators.

\subsection{Indicators of women's economic empowerment:}

According to Salem (2013), the indicators of women's economic empowerment include:

Qualitative indicators, such as activities and projects that help increase women's income, increasing women's chances of obtaining private income, improving women's skills and knowledge that enable them to compete in the labor market, women's participation in organizing and managing projects, gender equality in wages and salaries, the number of female workers in private and public sector projects and various administrative agencies, women's control over her own income, and increasing women's opportunities to obtain credit facilities and loans.

Quantitative indicators, such as self-dependence, making economic decisions, obtaining and controlling economic resources of the family, independence and economic security, securing and controlling opportunity and options, and having economic empowerment awareness.

\section{Methodology and Procedures}

\subsection{Method}

The author adopted the analytical descriptive approach for its relevance to the study objectives and its appropriateness to describe the reality of Saudi charities' contribution to low-income women economic empowerment, the obstacles that hinder this contribution, and the proposals to improve it.

\subsection{Sampling}

\subsubsection{Population}

The study population comprised (300) low-income women benefiting from the services provided by Bunyan, a charitable society aimed at women and family development, in Riyadh, KSA in 2018/2019.

Bunyan was chosen for several reasons:

- The large number of beneficiaries registered in Bunyan Society, which enables the author to collect the data required for the study.

- The society creates suitable training opportunities for low-income women in the fields of sewing and cooking to support women and their products. Therefore, the author can explore various types of activities and services provided to beneficiaries.

- The author can get in touch with Bunyan's specialists who can facilitate the data collection procedures.

\subsubsection{Sample}

The study sample consisted of (198) low-income enrolled in one or more of the activities and projects afforded by Bunyan for more than 6 months, the shortest period for implementing a project or attending a training in the society.

7.2.3 Instrument

The author prepared a questionnaire to measure the degree of charities' contribution to the economic empowerment of low-income women in Saudi society and the obstacles that hinder this contribution, and to introduce proposals to improve it. 
The initial form of the questionnaire was prepared with the help of some experts in the field of charitable societies and economic empowerment. Three-point Likert-type scale was used to rate participants' responses to the questionnaire items. Before each item appears three ratings: agree, neutral, and disagree and each rate has a corresponding numerical score, as shown in Table (1).

Table (1): The questionnaire rating using three-point Likert-type scale

\begin{tabular}{|l|c|c|c|}
\hline Response & agree & neutral & disagree \\
\hline Score & 3 & 2 & 1 \\
\hline
\end{tabular}

Table (2) explains the percentage of participants' response and its corresponding degree by the statements: very few, few, medium, high, and very high.

Table (2): Responses percentage and its corresponding degree

\begin{tabular}{|l|c|}
\hline Percentage & Degree \\
\hline Less than $50 \%$ & Very few \\
\hline $50 \%$ to $59.9 \%$ & few \\
\hline $60 \%$ to 69.9 & Medium \\
\hline $70 \%$ to 79.9 & High \\
\hline $80 \%$ or more & very high \\
\hline
\end{tabular}

Face validity

To verify the questionnaire validity, it was submitted to a panel of (7) experts specialized in the areas of charitable societies and women empowerment to evaluate the construct appropriateness to measure the study variables. The panel's opinions were considered by modifying the indicated items.

\subsection{Internal consistency}

To verify the items' internal consistence, correlation coefficients between the degree of each item and the total degree of the questionnaire were calculated, as illustrated in Table (3).

Table (3): Correlation coefficients between each item degree and the questionnaire total degree

\begin{tabular}{|c|c|c|c|c|c|}
\hline \multicolumn{2}{|c|}{ First domain } & \multicolumn{2}{|c|}{ Second domain } & \multicolumn{2}{|c|}{ Third domain } \\
\hline \multicolumn{2}{|c|}{ Item } & \multicolumn{2}{|c|}{ Item } & \multicolumn{2}{|c|}{ Item } \\
\hline 1 & 89. & 13 & 82. & 27 & 67. \\
\hline 2 & 82. & 14 & 73. & 28 & 82. \\
\hline 3 & 78. & 15 & 70. & 29 & 76. \\
\hline 4 & 39. & 16 & 64. & 30 & 64. \\
\hline 5 & 65. & 17 & 89. & 31 & 48. \\
\hline 6 & 70. & 18 & 55. & 32 & 89. \\
\hline 7 & 64. & 19 & 45. & 33 & 62. \\
\hline 8 & 89. & 20 & 82. & 34 & 78. \\
\hline 9 & 43. & 21 & 39. & 35 & 64. \\
\hline 10 & 45. & 22 & 68. & 36 & 55. \\
\hline 11 & 54. & 23 & 45. & 37 & 48. \\
\hline 12 & 57. & 24 & 48. & 38 & 39. \\
\hline & & 25 & 64. & 39 & 77. \\
\hline & & 26 & 66. & 40 & 54. \\
\hline & & & & 41 & 56. \\
\hline & & & & 42 & 78. \\
\hline & & & & 43 & 82. \\
\hline & & & & 44 & 64. \\
\hline & & & & 45 & 68. \\
\hline
\end{tabular}


The correlation coefficients occurred in the closed interval [0.39-0.89], indicating that all correlation coefficients are statistically significant at the significance level of (o.o1) and the validity of the questionnaire items.

\subsection{Reliability}

Cronbach's alpha was applied to the pilot sample responses to calculate the questionnaire reliability. The reliability coefficient was (o.92), indicating the high reliability of the scale.

The final form of the questionnaire consisted of two sections. The first section comprised (3) open questions, and the second section consisted of 45 closed items. It covered three domains: The degree of charities' contribution to low-income women economic empowerment in Saudi society (12 items); the obstacles that hinder charities' contribution to low-income women economic empowerment in Saudi society (14 items); and proposals to improve charities' contribution to low-income women economic empowerment in Saudi society (19 items). The questionnaire was designed using Google template and sent via the e-mail to (250) women benefiting from Bynuan for six successive months (from January 2019 to April 2019). Only (198) beneficiaries responded to the questionnaire.

\section{Results and Discussion}

To answer the first question: What is the level of low-income women economic empowerment in Saudi charities? beneficiaries' responses to the open-ended question demonstrated that Bunyan offers various activities aimed to raise the living conditions of the family members. It provides important programs for training, developing skills and securing sources of sustainable income. According to beneficiaries, productive families is the most effective program provided by Bunyan, in addition to many other useful activities, including:

1. Donation market: it seeks to encourage beneficiaries to recycle and maintain the denoting clothing and objects and to sell them to support their families financially, it is done every three months.

2. Home-based healthcare program: it is a six-month training program aims to train beneficiaries to care old people and patients with disabilities. It is implemented in collaboration with a national hospital and the College of Nursing at the University of King Saud.

3. Bunyan chefs: It is a very successful project with the largest number of beneficiaries trained to professionally prepare and serve food.

4. The children festival is hold every year to raise the level of awareness of Saudis towards children and to collect donations to support the activities provided for children.

5. Furniture recycle: it attracts a lot of women willing to renew and sell donating furniture.

Beneficiaries reported that Bunyan contributes to solving the problems facing the implementation of their projects and supports them financially. One of them said that "I think the most important service provided by Bunyan is helping us solve the problems that we face in the implementation of projects. I took part in Bunyan chefs and I encountered a problem in marketing the food I prepared, and thank God Bunyan's experts helped overcome this problem".

According to beneficiaries, Bunyan is keen on the development of low-income women's skills and abilities and qualifying them for the labor market to participate positively in the economic development. One of them reported that" training is the fundamental service provided. I received a set of training courses in design and cooking and I was thrilled by the support I got from the volunteering, talented Saudi ladies" 
Table 4: Means and percentages of the beneficiaries' responses to the first domain of the questionnaire

\begin{tabular}{|c|l|c|c|c|}
\hline \multicolumn{3}{|l|}{ First domain: The degree of practicing low-income women's economic empowerment by charities in Saudi society } \\
\hline S. & Item & Mean & Percentage & Degree \\
\hline $\mathbf{1}$ & $\begin{array}{l}\text { The charity takes all appropriate measures to provide job opportunities for low-income } \\
\text { women. }\end{array}$ & 1.5 & $50 \%$ & few \\
\hline $\mathbf{2}$ & $\begin{array}{l}\text { The charity develops low-income women's skills and capabilities in accordance with the } \\
\text { labor market requirements and qualifies them to participate positively in economic } \\
\text { development. }\end{array}$ & 1.5 & $50 \%$ & few \\
\hline 3 & $\begin{array}{l}\text { The charity provides economic services and programs for low-income women such as } \\
\text { monthly aids, goods, food, loans and productive projects. }\end{array}$ & 1.9 & $63.3 \%$ & Medium \\
\hline 4 & $\begin{array}{l}\text { The charity contributes to solving problems facing low-income women during project } \\
\text { implementation }\end{array}$ & 1.2 & $70 \%$ & High \\
\hline 5 & $\begin{array}{l}\text { The projects and services provided by the charity reduce poverty and unemployment } \\
\text { among low-income women }\end{array}$ & 1.2 & $70 \%$ & High \\
\hline 6 & $\begin{array}{l}\text { The charity encourages low-income women to produce some light commodities instead of } \\
\text { importing them }\end{array}$ & 6.2 & $86.67 \%$ & very high \\
\hline 7 & $\begin{array}{l}\text { The charity gives low-income women financial shares to implement their investment } \\
\text { projects }\end{array}$ & 1.2 & $70 \%$ & High \\
\hline 8 & $\begin{array}{l}\text { The charity guarantees low-income women a professional environment and suitable work } \\
\text { conditions such as expanding social protection }\end{array}$ & 4.2 & $80 \%$ & very high \\
\hline 9 & The charity provides human skills to plan and organize services for low-income women. & 1.2 & $70 \%$ & High \\
\hline 10 & $\begin{array}{l}\text { The charity publicizes its projects for low-income women on mass media and the available } \\
\text { communication channels. }\end{array}$ & 9.1 & $63.3 \%$ & Medium \\
\hline 11 & The charity is keen to survey women's opinion about the quality of the services provided & 5.1 & $50 \%$ & few \\
\hline 12 & $\begin{array}{l}\text { The charity coordinates with other charities in the society to provide distinguished services } \\
\text { for low-income women }\end{array}$ & 5.1 & $50 \%$ & few \\
\hline Total & 1.93 & $64,44 \%$ & Medium \\
\hline
\end{tabular}

Table (4) shows that the total response of low-income women benefiting from charitable societies to the items related to measuring the level of degree of practicing low-income women's economic empowerment by charities in Saudi society was medium with a percentage (64.44\%). Their responses' degree to items 1, 2, 11, 12, was few, while items $3 \& 10$ got a medium degree. Accordingly, the contribution of charitable societies to low-income women economic empowerment in Saudi society was medium, with a mean response of (64.44).

To answer the second question: What are the obstacles that hinder low-income women's economic empowerment in Saudi charities? The participating beneficiaries responded to this openended question. From their perspectives, most of the training courses and programs provided by the charity are not relevant to economy. One of them said that, "The cooking project includes funding school cafeterias and affords opportunities to open small stores, sewing and cooking are successful than other projects because do don't require having a certain level of education and they can easily find jobs in the future."

Another problem is that some projects require only one person, thus expansion becomes impossible and productivity is weak. Marketing is the biggest problem facing projects, in addition to lack of transportations that represent a huge challenge for some beneficiaries. Others face a very different problem, which is the lack of communication skills, as they cannot build new relations. One of the participants wrote, "the problem not getting access to clients, it may represent a problem in some cases, but for sure the social media can help solve it. The real problem the delivery of the product to the customers and a pretty larger problem is the transportation of these products".

Requesting a loan from the society requires a guarantor, this represents a challenge for many women. In some cases, the problem was the women themselves and their unwillingness to help themselves, thus they showed weak development. They did not attend the training courses because they would not give them access to decent jobs. One of the beneficiaries expressed her desire to become a beautician, however; she was afraid that the society would condemn her for working in this field. Other women were afraid of losing the benefits of social security if they got work. 
Table 5: Means and percentages of the beneficiaries' responses to the second domain of the questionnaire

\begin{tabular}{|l|l|c|c|c|}
\hline \multicolumn{3}{|c|}{ Second domain: Obstacles that hinder low-income women's economic empowerment in Saudi charities } \\
\hline $\mathbf{S}$ & Item & Mean & percentage & Degree \\
\hline $\mathbf{1}$ & $\begin{array}{l}\text { The conflict between the services provided by the charity to low-income women and the } \\
\text { government development plans }\end{array}$ & 5.1 & $50 \%$ & few \\
\hline $\mathbf{2}$ & $\begin{array}{l}\text { Poor coordination between the charity and other organizations to achieve the best use of } \\
\text { resources in implementing projects }\end{array}$ & 6.2 & $86.67 \%$ & very high \\
\hline 3 & $\begin{array}{l}\text { The prevalence of mediation and favoritism in the charity's distribution of services among } \\
\text { women }\end{array}$ & 1.5 & $50 \%$ & few \\
\hline 4 & $\begin{array}{l}\text { The governmental and legal procedures and conditions followed by the charity are } \\
\text { complicated for women's effective participation }\end{array}$ & 2.6 & $86.67 \%$ & very high \\
\hline 5 & $\begin{array}{l}\text { The charity is exposed to multiple financial crises that hinder it from providing services to } \\
\text { low-income women }\end{array}$ & 2.6 & $86.67 \%$ & very high \\
\hline 6 & The charity fails to develop marketing plans for productive families' commodities & 2.4 & $80 \%$ & very high \\
\hline 7 & The charity's lack of mass media and good communication channels with the public & 2.4 & $80 \%$ & very high \\
\hline 8 & $\begin{array}{l}\text { The charity does not afford transportation appropriate for transferring and promoting goods } \\
\text { to facilitate women's work }\end{array}$ & 2.6 & $86.67 \%$ & very high \\
\hline 9 & The charity's poor use of the available resources & $\mathbf{2 . 2}$ & $73.33 \%$ & High \\
\hline 10 & Lack of oversight and follow-up on the charity & $\mathbf{2 . 2}$ & $73.33 \%$ & High \\
\hline $\mathbf{1 1}$ & Imposing legal restrictions on foreign donors of aids and services & 2.6 & $86.67 \%$ & very high \\
\hline $\mathbf{1 2}$ & $\begin{array}{l}\text { The traditional perception of the importance of women work outside the home may make } \\
\text { them reluctant to participate economically }\end{array}$ & $\mathbf{2 . 4}$ & $80 \%$ & very high \\
\hline 13 & $\begin{array}{l}\text { Low-income women do not have confidence in their ability and competence to participate } \\
\text { economically }\end{array}$ & $\mathbf{2 . 5}$ & $3.83 \%$ & very high \\
\hline $\mathbf{1 4}$ & $\begin{array}{l}\text { The high-risk of some business and investment projects offered by the charity for low- } \\
\text { income women }\end{array}$ & $\mathbf{2 . 2}$ & $73.33 \%$ & High \\
\hline Total mean & $\mathbf{2 . 3}$ & $76.91 \%$ & High \\
\hline
\end{tabular}

Table (5) illustrates that the mean of the obstacles that hinder low-income women's economic empowerment in Saudi charities ranged from (50\%-86.67\%) with a total mean of 2.3 and a percentage $76.91 \%$, indicating a high degree of response. Items 2, 4, 5, 8 \& 11 obtained the highest degrees of response with a percentage of $86.67 \%$, followed by items $6,7,12 \& 13$. These items represent the main obstacles hindering low-income women's economic empowerment in Saudi charities. Items 1 and 3 obtained a percentage of $50 \%$ and ranked last.

To answer the third question: What are the proposed solutions to improve the level of low-income women economic empowerment in Saudi charities? the participating beneficiaries responded to this open-ended question. They proposed holding a regular meeting of the charity's members, volunteers from universities and specialists in the field of development to discuss the feasibility and financing necessary for the establishment of small and medium enterprises. If a family requesting a loan, it submits a work plan to be considered by the committee. According to one of the beneficiaries, "funding is the biggest support the family can have to develop its project. Besides, it is important to afford outlets for the products to provide consultations about production and marketing"

Some of the participating beneficiaries suggested solutions for overcoming these obstacles. To overcome the problem of marketing food products, they suggested supporting the family to open their own restaurant. They also suggested providing a stable financial support instead of loans. Among their suggestions, organizing workshops, seminars and training courses in cooperation with other charities interested in low-income women's economic empowerment to exchange experiences. 
Table 6: Means and percentages of the degrees of the beneficiaries' response to the third domain of the questionnaire

\begin{tabular}{|c|c|c|c|c|}
\hline \multicolumn{5}{|c|}{$\begin{array}{c}\text { Third domain: Proposals and suggestions to improve the level of low-income women's economic empowerment by } \\
\text { charities in Saudi society }\end{array}$} \\
\hline S. & \begin{tabular}{|c|} 
Item \\
\end{tabular} & Mean & percentage & Degree \\
\hline 1 & \begin{tabular}{|l|} 
Raising intellectual awareness of the true concept of economic empowerment and the \\
importance of low-income women's work and their participation in the national development
\end{tabular} & 2.6 & $86.67 \%$ & very high \\
\hline 2 & \begin{tabular}{|l|l|}
$\begin{array}{l}\text { Providing stable financial support, instead of loans, for low-income women's economic } \\
\text { empowerment }\end{array}$ \\
\end{tabular} & 2.6 & $86.67 \%$ & very high \\
\hline 3 & $\begin{array}{l}\text { Preparing rehabilitation program for supporting low-income women in the establishment of } \\
\text { their facilities and the promotion of their products in national and international markets }\end{array}$ & 2.4 & $80 \%$ & very high \\
\hline 4 & $\begin{array}{l}\text { Delivering workshops to improve low-income women's ability of making proper economic } \\
\text { decisions }\end{array}$ & 2.6 & $86.67 \%$ & very high \\
\hline 5 & Promoting the charity in the society to boost women's confidence of it & 2.2 & $73.33 \%$ & High \\
\hline 6 & The charity encourages low-income women to spell their needs and suggestions & 2.4 & $80 \%$ & very high \\
\hline 7 & Regular evaluation of programs and services provided to low-income women & 2.4 & $80 \%$ & very high \\
\hline 8 & $\begin{array}{l}\text { Delivering training courses to intense low-income women’s experiences in business } \\
\text { management, financial plan, and project expansion }\end{array}$ & 2.6 & $86.67 \%$ & very high \\
\hline 9 & $\begin{array}{l}\text { Providing more incentives for low-income women to encourage them to contribute to the } \\
\text { process of economic development }\end{array}$ & 2.6 & $86.67 \%$ & very high \\
\hline 10 & $\begin{array}{l}\text { Expanding the application of untraditional and flexible patterns of work, including part-time } \\
\text { work, home-based work, and flexible work hours }\end{array}$ & 2.6 & $86.67 \%$ & very high \\
\hline 11 & Forming lobbyist groups to influence officials to meet low-income women's demands & 2.4 & $80 \%$ & very high \\
\hline 12 & $\begin{array}{l}\text { Organizing seminars and training courses with other charities interested in-low income } \\
\text { women for the exchange of local, regional and international experiences }\end{array}$ & 2.6 & $86.67 \%$ & very high \\
\hline 13 & $\begin{array}{l}\text { Setting-up meetings with the region officials to discuss low-income women's issues and } \\
\text { needs }\end{array}$ & 2.4 & $80 \%$ & very high \\
\hline 14 & Using modern technology to plan and present various activities for low-income women & 2.2 & $73.33 \%$ & High \\
\hline 15 & The charity pays field visits to verify the conditions of female applicants for assistance & 2.6 & $86.67 \%$ & very high \\
\hline 16 & $\begin{array}{l}\text { The charity's use of updated database to get access to low-income women and thus } \\
\text { empowering them economically }\end{array}$ & 2.6 & $86.67 \%$ & very high \\
\hline 17 & $\begin{array}{l}\text { Conducting studies and academic research on the issues of women's economic } \\
\text { empowerment that suggest solutions to the recurrent challenges }\end{array}$ & 2.5 & $3.83 \%$ & very high \\
\hline 18 & $\begin{array}{l}\text { Arranging low-income women efforts to participate in defending rights before economic } \\
\text { decisions and policies makers }\end{array}$ & 2.6 & $86.67 \%$ & very high \\
\hline 19 & Developing personal, scientific and practical capabilities and skills among volunteers & 2.3 & $76.91 \%$ & Very high \\
\hline To & tal & 2.5 & $82.82 \%$ & very high \\
\hline
\end{tabular}

Table (6) shows that the total degree of the responses of low-income women benefiting from charitable societies to the items of the solutions proposed to improve the level their economic empowerment was very high with a percentage amounted to $82.82 \%$. The means of the solutions proposed to improve the level of low-income women's economic empowerment ranged from $73.33 \%$ to $86.67 \%$.

Accordingly, the proposals introduced to improve the level of low-income women's economic empowerment in Saudi charities were very good. Most proposals got a very high degree of beneficiaries' responses, except for proposals numbered 5 and 14 received high response.

\section{Discussion}

As shown from the results, the Productive Families sector plays an important role in the economy of Saudi low-income families. This sector plays an important role in the economic development of KSA, including the employment of national labor and the elimination of unemployment rates, especially among women. Although there are governmental efforts to alleviate poverty and encourage women to work, this appears to be hampered by the lack of a coordinated approach that targets economic productivity. In addition, there is much bureaucracy involved, due to the number of permits required, and time-consuming routine procedures (Al-Khamshi, 2011; Hartnell, 2018). 
The author believed that the lack of legislation and strong financial controls leads to many poorer families taking on loans from several sources and thus pushing themselves into further debt, which is contrary to the aims of these programs. In some cases, funds are disbursed to projects that have no connection with the program resulting in a deficit in the projects that could have productive outcomes.

Furthermore, the level of commitment that perhaps the government agencies were anticipating is missing; this may be due to financial support being regarded as a gift rather than a loan to be repaid through the success of the project, resulting in women taking the money without any intention of setting up a productive project. The moral and material support being offered by the current program is consequently insufficient to sustain the empowerment of women through economic productivity. This is in accordance with Shahri (2013) and Al-Aiban (2016) who emphasized the importance of bestowing women financial autonomy and skills to be economically empowered.

The women involved do not always realize the benefits of such training and consequently there are many missed opportunities. In addition, those who do want to progress and start up on their own are not given the resources they need once the training programs are finished. This is partly attributed to the lack of media information available that would encourage both moral and financial support. This goes in line with Al-Ghamdy (2019) and Aloulou (2017) who stressed the need for utilizing media to clarify the mission of NGOs and make the public aware of the effect of women employment. Saudi society still looks negatively on the concept of women employment outside the home, and their products are regarded as of little value. Many of the women who start the training programs are discouraged from becoming economically productive as it is against cultural norms. Likewise, Al-Khamshi (2011) and Nasseef (2015) agreed on the necessity of changing the mindset and negative social norms.

There is a general lack of experience on the part of the beneficiaries, who do not take individual responsibility for monitoring the projects and identifying the specific needs of their families. Most of the participants lack awareness of money management and the funding mechanisms available, and thus are not able to adequately support their needs. The author attributed this problem to women's limited skills and competence, as they need to attain more ongoing professional support and appropriate skills to become productive. They lack self-sufficiency and motivation to proceed on their own and need a much deeper level of input. This is in accordance with Nasseef (2015) indicating that the vital role played by Saudi NGOs in women's empowerment is to build their capabilities and upgrade their skills.

The marketing problem of women's products can be attributed to the fact that the internet is very far away from the family, so many productive families depend on different festivals for marketing, but these festivals are limited by their few returns and narrow time. In the long-run, most households are out of the market and cannot continue, and are replaced by other families and so on. This is a huge waste of supporters' money and the effort of families with incomparable returns, even if those funds and that effort were invested in small permanent projects that would have been better for families and economy.

There is a high level of competition in the local markets due to imported cheap goods from China, or from expatriate workers. Also, there is some reluctance by the owners of national factories to support the projects of these productive families, as a result of low quality of some products and the lack of commitment to continue to provide products, and competitive imported products. In addition, lack of sufficient marketing channels, lack of sufficient funding for these families to start their projects and lack of renewed development and innovation of these products.

Women also face high rents if they wish to exhibit their products at festivals and they are not in a position to compete with those who have large amounts of capital behind them. Furthermore, the reliance on selling at bazaars and markets means there are limited outlets for products, and these tend to be seasonal.

Surprisingly, there is no process for a feasibility study for each project. Although many of the women may be illiterate, there are specialist offices existing to offer support, yet these offices are not providing that support. Nor are the women receiving the help they need to market their products, 
despite agreements in place. There appears to be a lack of understanding of the level of need these women have. A feasibility study could also guide the women to more innovative projects rather than relying on traditional products that are regarded by Saudi society as having little value and may indeed be of a low quality.

It can be concluded that charitable institutions need to take appropriate measures to provide work opportunities for low-income women and to hold workshops and training courses for the development of their skills and abilities. Further, surveying low-income women's opinions periodically helps identify their needs and the degree of their stratification with the economic services and activities offered by the charity. Finally, establishing partnerships among charitable societies is essential for exchanging experiences in the field of low-income women's economic empowerment (Abdel'al, 2016; Salami, 2016; Yassin, 2018).

The obstacles that hinder charities from empowering low-income women economically include lack of coordination between charities and the other organizations, the complexity of the regulations, lack of transportation for facilitating women's work in the transferring of goods and the restrictions imposed on foreign donors. These obstacles reflect the reality of charitable societies in KSA and highlight the necessity for setting-up a future vision to improve the programs of low-income women's economic empowerment (Kazzouz, 2016; Peebles et al., 2015; At-Tarif, 2014; El-Sayed \& Amara, 2008).

For improving the level of low-income women's economic empowerment, the proposals introduced by the author were highly accepted by the beneficiaries. Charitable societies may adopt these proposals and work fast to enable low-income women economically and achieve social development (Salami \& Beeh, 2013; Najm, 2013).

\section{Conclusion}

This study aimed to identify the degree of the economic empowerment of Saudi women with lowincome in charitable institutions and outline its obstacles. Analyzing the participants' responses to the questionnaire showed that there was a medium level of charities' contribution to low-income women's economic empowerment in Saudi Arabia. Further, there were a set of obstacles hindering low-income women's economic empowerment, including lack of coordination between charities and other organizations, complexity of the regulations, and lack of transportation allocated for facilitating women's work. The study also introduced some proposals to improve the level of low-income women's economic empowerment, such as providing training programs for raising low-income women's awareness of their social and economic rights and developing their skills of initiation, taking decisions, marketing, and management. In addition, coordination between Saudi charities to establish business incubators for marketing and promoting low-income-women's local products can be effective in encouraging and supporting them.

\section{Recommendations}

In the light of the study results, the author concludes by a set of recommendations. First of all, the true conception of economic empowerment needs to be effectively and practicing applied in line with the goals and objectives of charitable societies. For low-income women, there is a dire need to prepare and provide more programs and training courses for raising their awareness about their rights of economic empowerment and the ways of its achievement by developing their skills of initiation, taking decisions, marketing, and management. For charitable institutions, the programs they provide for low-income women economic empowerment should be revised and redeveloped in the light of empowerment standards and indicators. They need also to cooperate with financing institutions and official organizations to create local, regional and international networks for the projects run by poor women. In addition, setting-up business incubators for marketing and promoting low-income-women's local products is highly recommended for solving the problem of marketing. Further, it is important to create a database for all Saudi charities that combine the required information about low-income women as this helps have access to them and providing them 
with the proper services and financial donors. The study also highly recommends constructing partnership between civil society organizations and government institutions, and between national and international charities for figuring out new strategies for women's empowerment and working together to overcome the challenges. On the level of the individual, more efforts should be done by media campaigns and social programs aimed at disseminating the culture of volunteering, educating people about women's right, and correcting the prevailing misconceptions and traditions about woman work. As such, improving women's economic development in the Saudi society requires working on the individual, social, and institutional levels.

\section{Acknowledgement}

The author would like to thank the Center for Promising Research in Social Research and Women's Studies and Deanship of Scientific Research at Princess Nourah bint Abdulrahman University for funding this research project in 2020.

\section{References}

Abdel'al, M. (2016). Effectiveness of small funding institutions in women economic empowerment from the perspectives of institutions' managers and beneficiaries (Master thesis). Faculty of Post-Graduate Studies, AnNajah University, Nablus: Palestine.

Abdelrazq, A., Hamad, S., Ali, M., Mohammed, F., \& Kamal, W. (2016). The Application of Instagram as a Promotional and Communication Tool by Productive Families in Bahrain. International Journal of Technology Diffusion (IJTD), 7(3), 21-32.

Abdul Salam, S. (2005). Non-governmental organizations working in the field of women empowerment. Al-Ein House for Publishing, Cairo: Egypt.

Adraghmah, T. (2014). Effectiveness of the training provided by feminist institutions in the economic empowerment of Palestinian women from the beneficiaries' perspective (Master thesis). Faculty of Post-Graduate Studies, AnNajah University, Nablus: Palestine.

Aguirre, D., Hoteit, L., Rupp, C., \& Sabbagh, K. (2012). Empowering the Third Billion: Women and the World of Work in 2012. San Francisco: Booz and Company.

Al-Aiban, N. (2016). The need to establish a social development organization to support productive families (Unpublished doctoral dissertation). King Saud University, Saudi Arabia.

Al-Ghamdy, F. (2019). Role of non-profit organizations in Riyadh in achieving sustainable social development in the light of the vision of Saudi Arabia 2030 field study (Unpublished doctoral dissertation). King Saud University, Saudi Arabia.

Al-Khamshi, S. (2011). The reality of the projects of families in the KSA and the entrance of the empowerment of women heads of households (Unpublished doctoral dissertation). Princess Nourah University, Riyadh.

Al-Kharouf, A., \& Al-Hadidi, S. (2011). The Project of Women Developmental Prosperity in Relation to Jordanian Women Empowerment: An Evaluative Study. Human and Social Sciences, University of Jordan, 38(1), 240-267.

Aloulou, W. (2017). Enhancing women's economic empowerment through entrepreneurship in Saudi Arabia. In E. AlA'ali, M. Al-Shammari \& H. Masri (Eds.), Arab Women and Their Evolving Roles in the Global Business Landscape )pp. 120-151. ( Hershey, PA: IGI Global. doi: 10.4018 / 978-1- 5225-3710-6.choo6.

Akour, I. (2015). The reality and prospects of women economic empowerment: The Jordanian Ministry of Labor as a model. Available at: https://alolabor.org/wp-content/uploads/2016/o1/Tanmya_N_Jordon_20_22_12_15 _W_P_Iman_Akwar.pdf?amp=1

Amal, A., Halwas, R. Najar, S., Shukry, A., Ketab, E., \& Amrah, E. (2013). Rural women and local development: Regional synthesis report: Tunisia, Palestine and Jordan (Edited by Reem Al-Jabi). Arab Women Center for Training and Research, Kawther.

At-Tarif, G. (2014). Obstacles of Saudi Women empowerment in the Labor Market. The Future of Arabic Education, 88(11), 107-108.

Derbal, N. (2011). Philanthropy in Jeddah, Saudi Arabia Lifestyle and Liberty in the Name of Piety and Islam. Paper presented at Takaful 2011: The first Annual Conference on Arab Philanthropy and Engagement. Amman, Jordan. April 16-17.

El-Sharif, I., \& Albraithen, M. (2018). Adoption of recent social technologies as enablers for productive families: Case of Saudi Arabia. Journal of Education and Practice, 9(8), 73-81.

El-Sayed, H., \& Amara, T. (2008). The role of non-governmental organizations in poor women empowerment to deal with the mechanisms of the labor market. Social Service and Human Studies, 24(3), 35-44. 
Hartnell, C. (2018). Philanthropy in the Arab region: A working paper. Retrieved from: https://www.alliancemagazine.org/wp-content/uploads/2018/o3/Philanthropy-in-the-Arab-region-March-2018.pdf

Hoque, M., \& Yoshihito, I. (2009). Women empowerment through participation in micro-credit program: A case study from Bangladesh. Journal of Social Sciences, 5(3), 244-250.

Hunt, A., \& Samman, E. (2016). Women's economic empowerment: Navigating enablers and constraints. Development progress: London.

Kandy, K. (2017). Are Women More Risk Averse? Economic Inquiry, 36(4), 620-63o.

Kashroud, S., \& Marzouki, O. (2019). Economic empowerment of the Algerian women: A human right and development bet. Ijtihad Journal for Legal and Economic Studies, 8(1), 490-513.

Kazim, T. (2016). Obstacles of women empowerment in the Iraqi society: A field study at the University of Qadisiyah. Journal of the University of Babylon: Humanities, 24(2), 956-972.

Kazzouz, F. (2016). The obstacles of Libyan women economic empowerment and proposed solutions: Case study( Master thesis). Faculty of Post-Graduate Studies, Universitas Islam Negeri Maulana Malik Ibrahim Malang.

Khan, A., \& Bibi, Z. (2011). Women socio-economic empowerment through participatory approach: A critical assessment. Pakistan Economic and Social Review, 49(1), 133-148.

Khoury, A., Mukhual, M., \& Hadeer, N. (2013). The reality and prospects of women empowerment in Syria. The University of Tishreen's Journal of Studies and Research, economic and legal sciences series, 28(2), $223-243$.

Maaytah, R. (2010). Gender and women empowerment in the Arab world. Organization of Arab Women, Cairo: Egypt.

Mohamed, M. (2007). Civil societies' contributions in building the capacities of new women candidates for local councils. Social Service and Human Studies, 5(23), 26-38.

Mohamed, H. (2004). The role of women societies in women empowerment of social life. Social Service Studies, 16(3), $17-28$.

Najm, M. (2013). The role of development institutions in Palestinian women empowerment: An analytical study of strategic plans and annual reports in the light of empowerment standards and indicators. Islamic University Journal for Educational and Psychological Studies, 21(3), 239-276.

Nassar, N., Khafagy, F., \& El-Khouly, R. (2017). Arab Women Economic Empowerment and its relation to basic education. Available at: http://efuegypt.org/Pics/dwn1652019543842.pdf

Nasseef, K. (2015). Women empowerment strategies in NGOs in the city of Jeddah, Saudi Arabia-exploring the complexity and challenges of the cultural context (Doctoral dissertation). University of Leeds.

OECD. (2011). Women economic empowerment, Issues Paper DAC Netwwork on Gender Equality (GENDERNET).

Peebles, D., Darwazeh, N., Ghosheh, H., \& Sabbagh, A. (2005). Factors Affecting Women's Participation in the Private Sector in Jordan. National Center for Human Resources Development, Jordan. 1-64.

Rahman, S., \& Sultana, N. (2012). Empowerment of women for social development: A case study of shri mahila griha udyog lijjat papad, Hyderabad district. Authors World, Journal of Arts, Science \& Commerce, 3(1), 50-59.

Saif, M. (2010). Introduction to the study of Saudi society. Al-Khuraiji House for Publishing and Distribution: Riyadh, Saudi Arabia.

Salami, M. (2016). Women and the problem of economic empowerment in Algeria. The Algerian Journal for Economic Development, 5(3), 183-202.

Salami, M., \& Beeh, E. (2013). The role of small and medium institutions in women economic empowerment in Algeria. Performance of the Algerian Institutions, 11(4), 47-73.

Salem, A. (2013). The determinants of empowering rural breadwinner women in the Egyptian rural (Master thesis). Faculty of Agriculture, University of Fayoum, Egypt.

Saqib, N., Aggarwal, P., \& Rashid, S. (2016). Women economic empowerment growth: Empirical evidence from Saudi Arabia. Advances in Management and Applied Economics, 6(5), 79-85.

Shahri, F. (2013). The role of productive families' programs in reducing the poverty of Saudi women: A study applied to social security beneficiaries in Riyadh region (Master thesis). Imam Muhammad bin Saud Islamic University.

Topal, A. (2019). Economic reforms and women's empowerment in Saudi Arabia. Women's Studies International Forum, 76, 102253. https://doi.org/10.1016/j.wsif.2019.102253

UNFPA. (2005), Guidelines on Women's Empowerment, Prepared by the Secretariat of the United Nations InterAgency Task Force on the Implementation of the ICPD Program of Action.

Women in management and leadership in the KSA. (2017). Account Ability \& Glower. Available at: https://www.accountability.org/wp-content/uploads/2017/o6/AA-GW-Final-report-English.pdf

World Economic Forum. (2017). The Global Competitiveness Report 2017- 2018: Insight Report, Edited by Klaus Shwab. Geneva, WEF.

Yassin, S. (2018). The Impact of Women Empowerment Decisions in the KSA on the Financial Markets and Business in Accordance with Vision 2030: Applied study to female employees in Saudi Institutions of Abha City. Faculty of Islamic and Arabic Studies Journal, 3(4), 493-910. 